
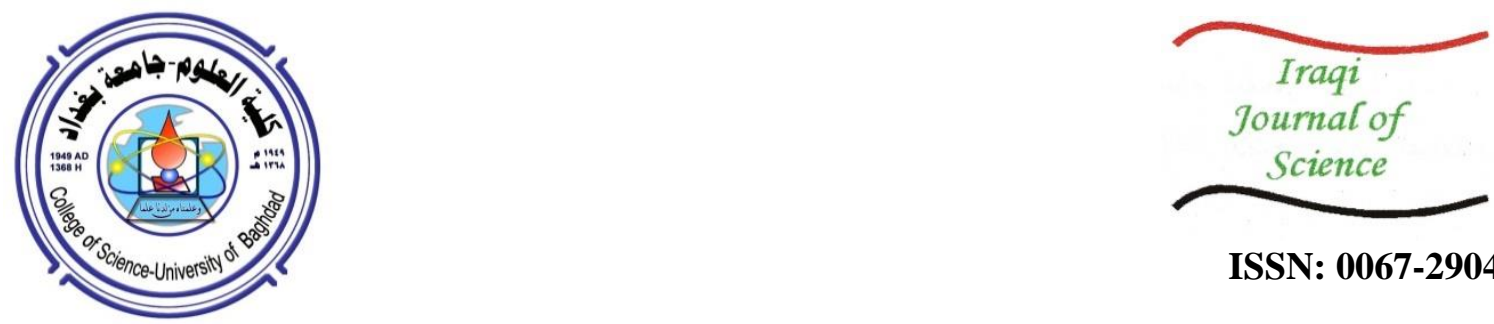

ISSN: 0067-2904

\title{
Automatic Extraction of Unmanned Aerial Vehicles (UAV)-based Cadastral Map: Case Study in AL-Shatrah District- Iraq
}

\author{
Hussein F. Difar ${ }^{1 *}$, Fanar M. Abed ${ }^{2}$ \\ ${ }^{1}$ College of Engineering, University of Baghdad, Baghdad, IRAQ \\ ${ }^{2}$ Honorary member of the University of Exeter, Exeter, UK \\ Received: 18/4/2021 \\ Accepted: $13 / 7 / 2021$
}

\begin{abstract}
Cadastral map environment is directed, more than ever before, towards Artificial Intelligence use to produce fast and accurate maps and keep up with the huge population growth. The traditional approach currently in production of maps is expensive and effort-intensive in addition to be considered as highly timeconsuming process. UAV-based cadastral mapping imagery that use automatic techniques are newly being exploited to accelerate the process of production or updating. The state-of-the-art intelligent algorithms are capable to extract land boundaries from images better than conventional techniques. This paper presents an automatic workflow of cadastral map production based on land boundary and automatic feature extraction from UAV-based imageries. The developed workflow involved four steps: (i) Flight planning and Ground Control Points (GCPs) observation, (ii) image pre-processing, (iii) image segmentation (iv) boundary detection and extraction (classification), (v) postprocessing, and (vi) accuracy assessment. The study area includes geometrical and affect spectral reflectivity (slums) covered by 206 images those captured using a quad-rotary UAV (DJI Phantom 4 pro). The mosaic image of the Area of Interest (AOI) was produced by following Structure from Motion /Multi-view Stereo (SfM-MVS) photogrammetry which covers $0.592 \mathrm{~km}^{2}$ ground area using pix4DMapper software. The MultiResolution Segmentation (MRS) algorithm was applied for object generation and later both spectral and geometrical information (area, brightness, border and the normalized digital surface model NDSM)) utilised to extract the boundaries by Object Based Image Analysis (OBIA) rule-based expert systems in eCognition software. The most exciting challenge in this AOI was buildings separation depending on number of buildings using the QGIS software. The accuracy assessment of the obtained results showed that $88 \%$ of the extracted boundaries were correct following automatic extraction routine when compared to manual digitizing. This approach can highly compensate time, efforts, and low accuracy outcomes from traditional surveying and manual registration approaches applied in Iraqi institutes nowadays. The presented approach can definitely help to speed up map production phase and keep pace up with population expansion and modern technologies.
\end{abstract}

Keywords: UAV photogrammetry, SfM-MVS-photogrammetry, Automatic feature extraction, MRS segmentation, Cadastral Mapping, Pix4D, eCognition.

انتاج خارطة مساحية ألياً من صور الطائرات بدون طيار : منطقة الدراسة في مدينة الثطرة ـالعرق

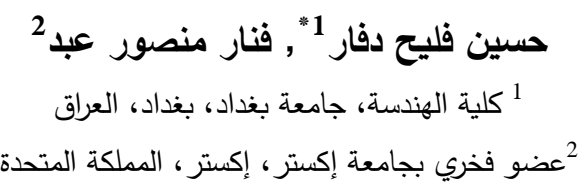

*Email: husseinalzidy@gmail.com 


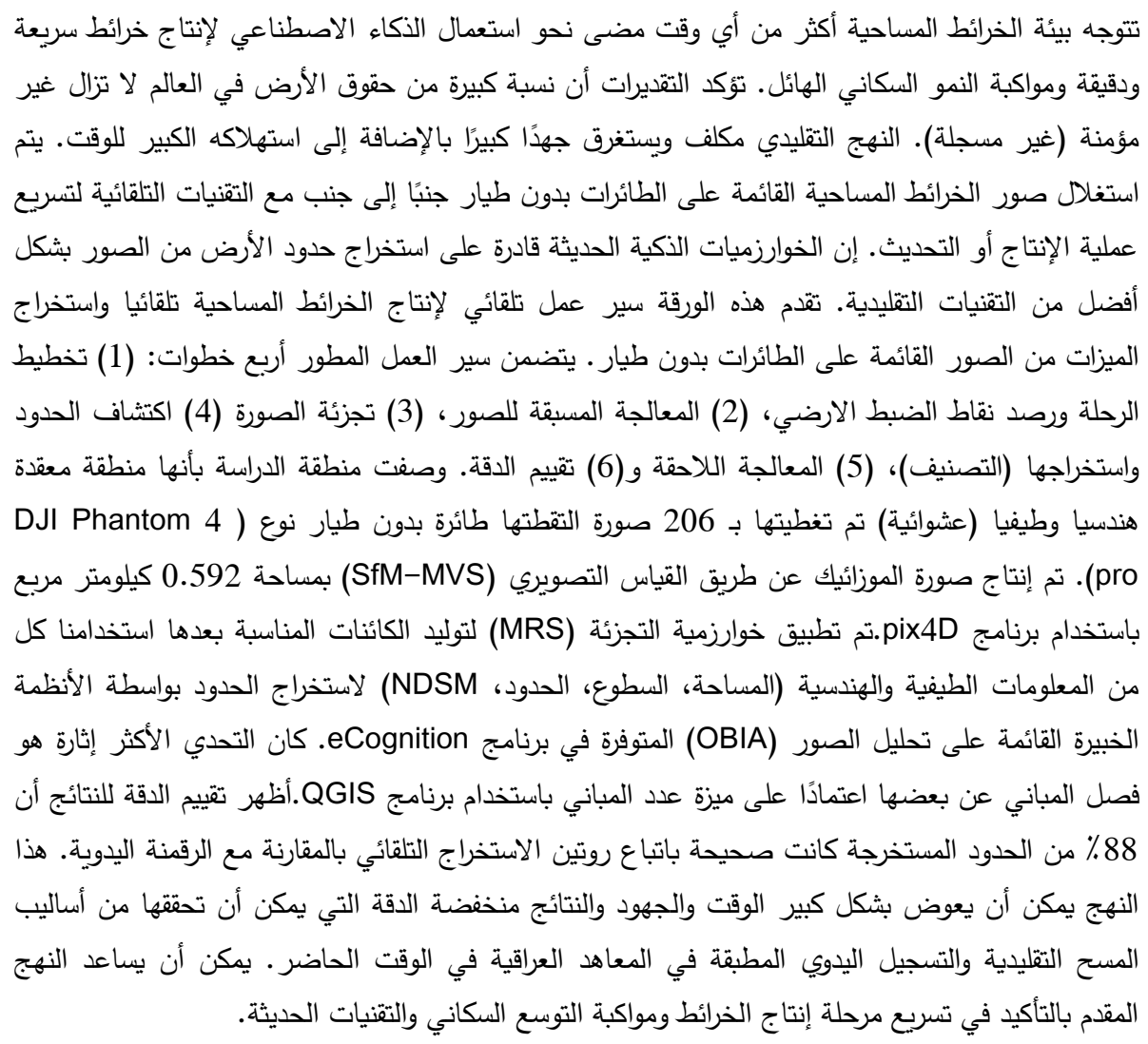

\section{Introduction}

Today about $75 \%$ of the land around the world is not registered or notarized in an official legal cadastral registry as most are located in developing countries [1]. Further, about 90 countries do not have a land registration system and about 50 countries are already in the process of establishing these systems [2]. This increase in occupation of insecure lands and therefore occurrence of conflicts is due to the low percentage use of modern map production techniques and only relying of traditional old survey techniques which cost time, efforts and high budget. Another reason for these land properties conflicts, especially in developing countries is due to relying on old maps (reference maps) that interfere with real land boundaries due to unavailability of any updating process or even relying on low-resolution satellites imagery to produce new maps that may be deliver low accuracy level due to lowquality images [3]. In the past, production of cadastral maps was established by traditional methods, where the ground (field) survey is applied by taking measurements on the ground in direct contact with the target and using old survey tools such as tape measures. Extraction process of Cadastral boundaries cost a lot of money and also time consuming, in addition to the need of a large number of workers and surveyors in the field [4]. It is clear in the developed and developing countries that urbanization is increasing rapidly for various reasons, especially growth of cities linked to determining agricultural or non-agricultural land boundaries [5]. The data resulting from the traditional survey has become insufficient. In the context of economic development, there has become a diversified of the required information, and the data stored in the classic survey systems failed to meet requirements of future vision due to difficulty of conducting analysis on data such as decision-making [6]. A solid Cadastre system is an important part of securing property rights and economic development and urban planning for the country, as financial and human capabilities represent an important role in establishing this system [7]. Obtaining accurate data of properties in general has a great 
importance in any management system. Therefore, it is important to find modern technologies that are more accurate, faster, and more flexible to adopt Cadastre systems.

With the emergence of remote sensing technology, that provides a massive opportunity in cadastral mapping, in addition to the Global Positioning System (GPS) high accuracy with several observation approaches, the tendency to exploit these technologies and employ them in the field of cadastral map has increased dramatically [8]. Several growing countries witnessed the need to accelerate the cadastral maps production. The development of modern technologies such as remote sensing (satellite and aerial imagery) greatly contributed to the improvement of the cadastral map production, since then researchers started to investigate how to exploit these techniques in Cadastral mapping systems. In the beginning, remote sensing was used to extract visible cadastral boundaries through manual digitization, which is traditional method used in map production process. This process is time-consuming and expensive, and also needs skilled operators. In addition to other factors, this technique still adopted in most countries, including Iraq. This method was used to eliminate the efforts resulting from only relying on ground surveying and field measurements which was common at the time.

The need for a more efficient and rapid mapping technique increased gradually to overcome the problems of the manual methods [9]. With the help of computer vision, algorithms are developed to automatically extract the cadastral boundaries, however, extracting boundaries was first semi-automatic (the remainder of the boundaries is completed manually). Latter process was developed to become automatic [10]. From here, a new era begins with the process of map producing, especially the cadastral, which is characterized by short time, less cost and high accuracy techniques. The high-resolution images (GSD up to a centimeter) taken by Unmanned aerial vehicles (UAVs) helped to dramatically improve the accuracy of the produced maps, that became more common than satellite images because of inexpensive, fast and reachable technique to produce Cadastre systems [11]. Studies showed that the cadastral maps, derived from UAV aerial images showed that the geometric accuracy delivered from these close-range remote sensing technique is approaching or sometimes better than accuracy, delivered from applying pure cost and time consuming accessible land traditional methods and therefore was adopted to be the preferred technique for Cadastre system extraction in the world[2,12] . The Trimble ${ }^{\circledR}$ eCognition ${ }^{\circledR}$ Suite is one of the most comprehensive software in the number of processing algorithms with high and varied performance, non-open-source programs.

the eCognition ${ }^{\circledR}$ is a developed analysis software available for applications of geospatial. It is designed to enhance, automate and accelerate a variety of geospatial data interpretation and allows users to design features extraction or solutions of change detection to transform geospatial data into geo-information. eCognition imports several geospatial data, merge (fusing) them together into a wealthy stack of geodata for analysis and the possibilities are endless (such as spectral data, 3D structure from point clouds data and spatial or thematic data from GIS vectors. The analysis logic is organized into steps series to make a computer-based representation of an expert's geo-spatial interpretation proceeding, known as a Rule Set[31,32]. eCognition is software Object-based image analysis (OBIA) software that is in principle appropriate for use in all areas of remote sensing and the capacity to handle perhaps the most complex remote sensing works[13],see Figure 1.

eCognition is distinguished by the high-perform segmentation and classification algorithms. The perfect power of eCognition's environment for data analysis - combine OBIA techniques with state-of-the-art Deep Learning, point cloud, merge raster and vector data within a single project for hardy analyses[14]. We can develop rule- sets and workflows for advanced segmentation to classification and feature extraction. eCognition classifies and analyzes imagery, point clouds and vectors using all the information needed to describe it 
correctly[15]. Rather than examining pixels or points individually. The closeness of eCognition to GIS, its ability to join and combine the available data in analysis with the straight-forward results export to GIS this help eCognition users to obtain excellent (amazing) results [32].

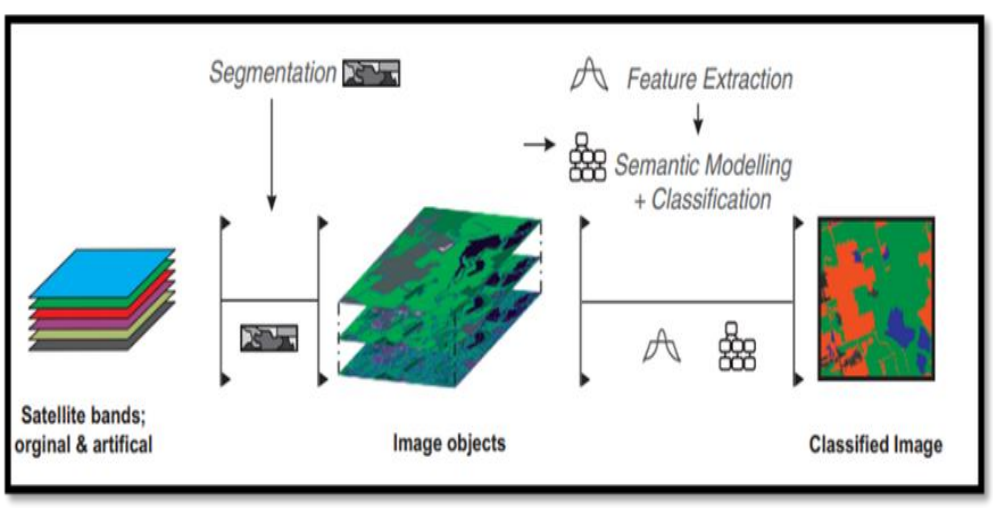

Figure 1-Workflow of object-based image analysis in eCognition

\section{Study Description}

The study area is located in Iraq-Thi-Qar Governorate-Al-Shatrah District, which is approximately $350 \mathrm{Km}$ away from Baghdad the capital city of Iraq, see Figure 2.

This sample was selected because it provides a comprehensive overview of the spread slum (or unauthorized) areas in the country that were established as a result of converting agricultural lands to residential without official approvals. This challenge has faced any maps updating projects since the expansion of illegal residential properties have increased dramatically after 2003 in overall Iraq. This is happening as land owners tend to divide their property into smaller sections and sell them to desired customers without following any urban design standards. This leads to creating unequal, irregular and sometimes overlapping areas with each other. Further, the new illegal extracted residential area is usually similar in build material (rooftops, roads and streets is dirt), which generated a spectral complexity from a cadastral perspective and represents a major challenge for cadastral map production.

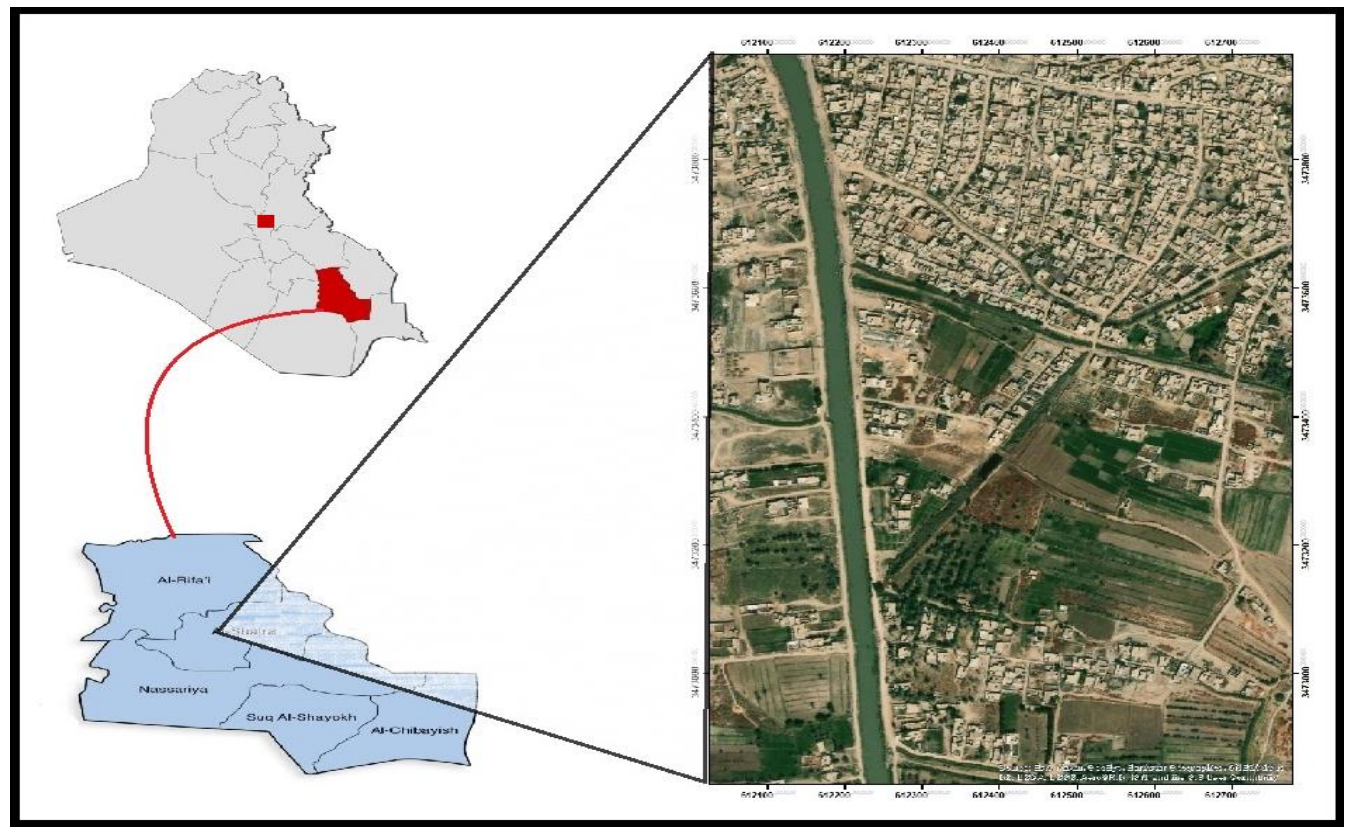

Figure 2-Location of the study area. 


\section{Cadastral Maps in Iraq}

Integrating and standardizing coordinate systems in Iraq are considered the main challenge that face map expertise in Iraq to produce any national cadastral map. The production of national cadastral maps in Iraq has passed through several stages starting from the old English system, or Nahrawan Datum 1934 system (the first coordinate network in Iraq), where the point of origin was in the Nahrawan region southeast of Baghdad. After the system transformed to the new English system in year 1967, and lastly in 1974-1979 through the national well-known project carried by the Pole Service Company with the reference point lies in Karbala province [16][17].

Cadastral maps in Iraq are produced and integrated from all these conflicts coordinate systems in several scales starting from 1:500 to 1:500000 and more often 1:100000, 1:20000 and 1:5000 to clarify the boundaries of the original plots, provinces, districts and sub-districts. Unfortunately, the current cadastral reference maps in Iraq cannot keep tracking rapid urban changes at present time. This is due to rapid growth in urban activities and a large number of land divisions into smaller plots, and no new production or even updating map projects has been generated since the last project carried by the Pole Service [18]. During this long period, the earth has undergone geological changes such as changing the course of the rivers and shrinking or expanding Shatt al-Arab path which causes problems in the national land management and even affect the international boundary mapping with regional countries. Nowadays, official institutions in Iraq are using manual methods in process of map updating for individual use only when the majority of these manual methods are based on low quality satellite images. They usually match the reference map with satellite images to manually determine the ownership or land boundaries, and this dramatically increases the accumulation of resultant errors in the produced map. Another reason for this increase in errors is due to the use of low-precision devices such as navigator (GPS) devices in fieldwork for settling property disputes. Further, most of the ground control points have been damaged or some have been removed due to people abuse or ignorance as there is no continuous maintenance to keep these points in healthy status.

Therefor; there is an urgent need to create or update cadastral maps in Iraq to reduce the problems caused from random integration of old maps and disorder in the division of lands without any technological solutions to end property disputes which still increased by time. The existence of new cadastral systems that provide complete information about any plot of land through the establishment of digital databases requires concerted efforts of all specialized and supportive institutions to bring this essential national project to life[19]. What can increase the desire to continue implementing this project, is the availability of a set of modern and accurate technologies that can dramatically accelerate the production process and speed up project workflow implementation such as UAVs and Differential global positioning system (DGPS)[20].

\section{Material and Methodology}

This stage involves project planning and preparation considering following technical aspects:

- $\quad$ Area investigation: It is of great importance for a close-up knowledge of the existing landmarks that the area can be explored in images provided by Google Maps. However, this is not always sufficient, as exploring the area region in field with images in hands gives a complete knowledge (visualization) of the area.

- Distribution of GCPs: Checking that GCPs are covering the entire area correctly is very essential. The GCPs distribution must take into considerations avoiding high buildings and dense trees to secure the appearance and identification of the points fast within the images. As well as avoid placing the points along a straight line is very important in order to avoid error accumulations. Using DGPS technique for point observation in high accuracy[21], then correct it by the OPUS (Online Positioning User Service) website (free). 
- $\quad$ Overlap between aerial images: Overlap assurance between images (end lap and side lap) with a sufficient percentage is very important because it allows every physical object to appear in a number of images, that generates a stereoscopic image to complete the mosaic production as well as to avoid looseness as a result of weather conditions or any related problems [22].

- The Ground Sampling Distance (GSD) determination: Based on the required resolution, GSD=1/image resolution. Therefore, the greater the resolution, the smaller the GSD value delivered.

- $\quad$ Flight height: Determining the flight height is very important in covering the required area, the higher the height, more desired area coverage and vice versa. However, flying height has an inverse relationship with GSD. Thus, GSD decreased wherever flying height increased. - $\quad$ Type of UAV platform: UAV platform type affects different flight parameters such as area coverage, overlap percentage, GSD value, data capture modes as well as flying height. All these parameters are therefore affecting project overall cost in respect to budget, time and also operator efforts. Therefore, when the project area is large, it is recommended to fixed wing-UAV rather than utilizing rotary wing aircraft, see Figure 3.

\section{Data Collection}

The stage of obtaining field data is very important because it establishes a database for any project where outputs are built, especially in projects which need accurate results such as cadastral map production. This stage includes two steps:

i) Field Surveying: In case there is a requirement to achieve specific accuracy standards, georeferencing is needed for the final result. This requires collecting accurate GCPs measurements. Ground control points are measurement with the use of high accuracy equipment such as differential global positioning system (DGPS). We were not able to use and reference targets to show the GCPs of images due to the harassment of the Landowners to identify the corners of some buildings as reference targets, see Figure 4.

The selection of GCPs must cover the scene for at least four points or more. Seven points were observed, four in area study and three outside it, see Figure 5. We used GPS Topcon GR3 in the observation. Then it was corrected by sending a file RINEX (Receiver Independent Exchange) to OPUS. That will be used in the process of georeferencing.

ii) Image Acquisition: The area was covered by a number of flight lines with a flying height of $100 \mathrm{~m}$, with a side and front overlap of $60 \%$, GSD of $2.6 \mathrm{~cm}$ and an area of $0.592 \mathrm{~km}^{2}$. The total number of images covered the site was 209 images. The autopilot application used was Pix4Dcapture (C) (www.pix4d.com) which is a free mobile application allowed you to easily add, edit and adjust flight parameters in the field. The data capture campaign was applied in March 2020 during Covid-19 pandemic partial curfew in Iraq. Data were collected by a UAV Phantom 4 Pro drone from the DJI Company (www.dji.com), as shown in Figure 6. After completion, the images are reviewed to ensure their quality and prepared for the image processing stage. 


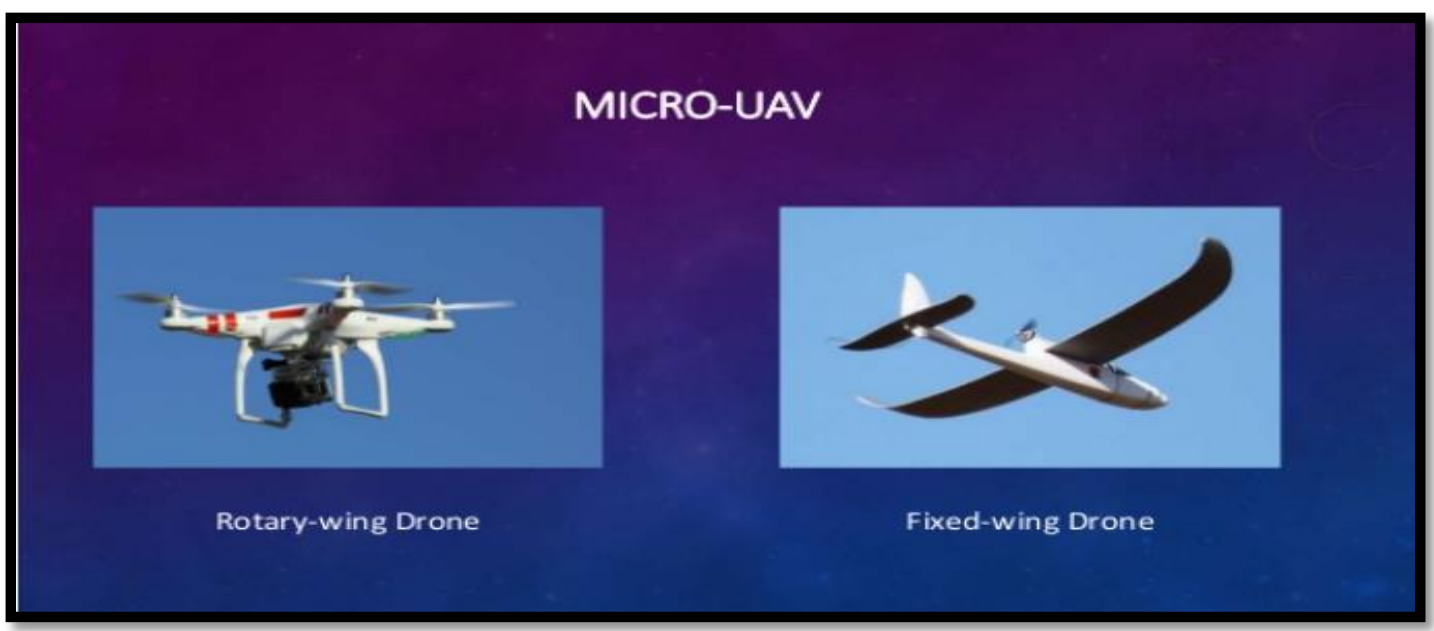

Figure 3-Illustrate UAV fixed wing and rotary.

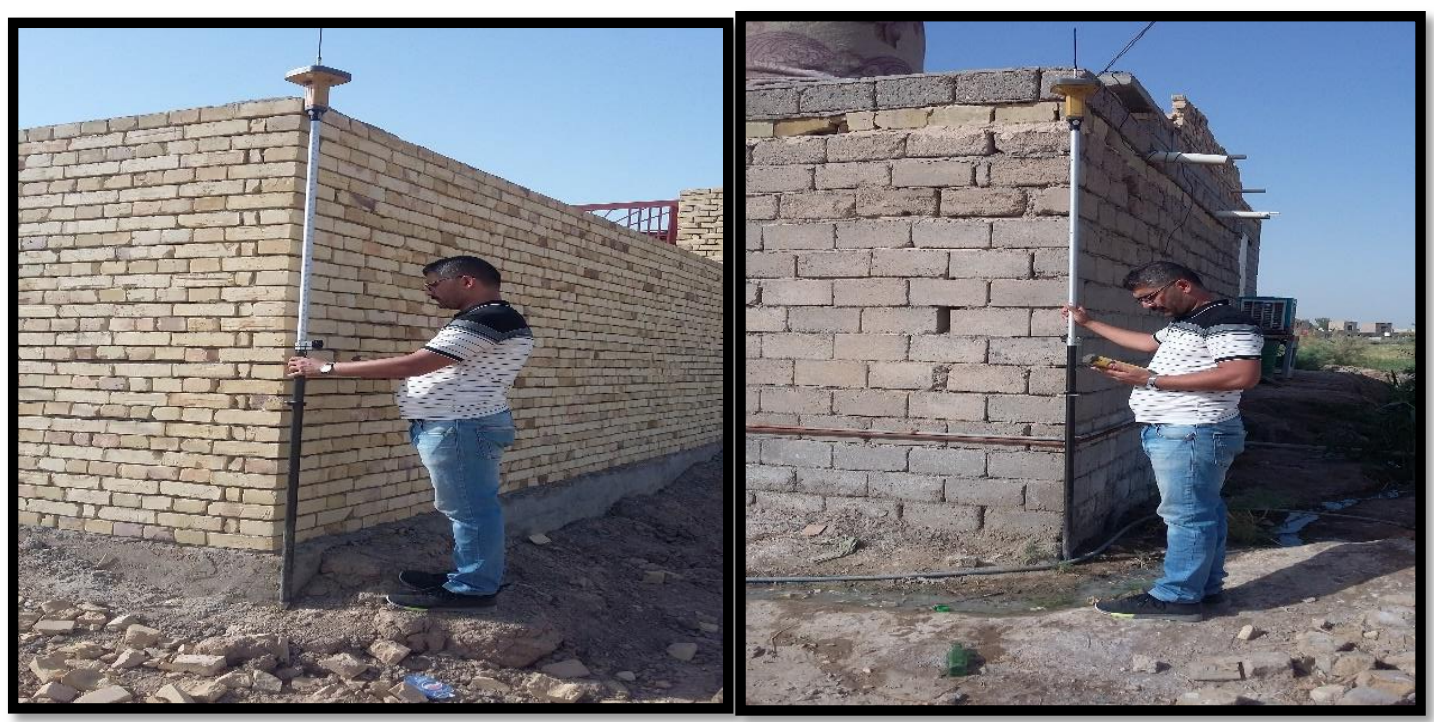

Figure 4-Illustrates adopting the corners ofsome buildings to be reference targets to GCPs observation.

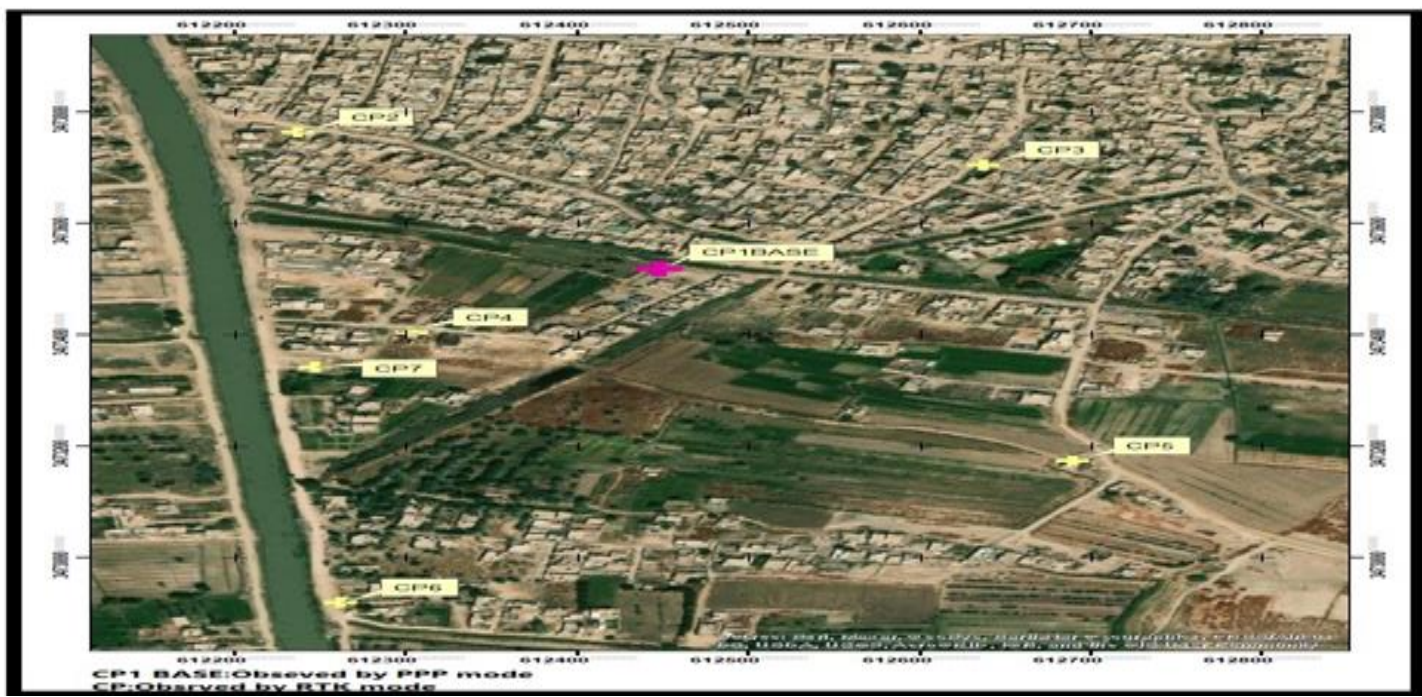

Figure 5-Shows GCPs distribution and observation mode. 


\section{Data Processing and Ortho-mosaic Generation}

Following image acquisition, it is necessary to perform post-processing operations and adjustment computations to project the 2D image data into 3D space and compensate the effects of systematic and random errors exposed from data capturing process. The purpose of image processing (radiometric and geometric adjustment) is to increase the ability to interpret and analyze features and display the results accurately in a statistical manner. To do so, Pix4D mapper was used, which is a structure from motion (SFM) high-performance software available to process large number of images automatically and has a seamlessly approach and simple user processing workflow. Pix4D is a photogrammetric software enables the mapping of medium to large areas rapidly, saving a lot of time, deliver accurate results, and also accepting more interaction from end user. Pix4Dmapper's algorithms convert your ground or aerial images to digital map and generate 3D model representation (point clouds, terrain or surface models, orthomosaic). It provides a quality report involving practical and detailed editing tools, ground control points, checkpoints and all input and output processing. The Automatic aerial triangulation (AAT) technique is used to process UAV images, which is a fully automatic approach, except for image-geo-tagging process which was applied semiautomatic. AAT is defining the relationship between camera, image and the ground where all must lie along a straight line (mathematical relationship). This can provide accurate information about the photographed area. The Bundle block adjustment (BBA) application following the AAT approach includes interior and exterior (IO and EO) camera parameters calculations through the triangulation process. At the end of this process, the software calculates the initial positions of the images that were taken by (GPS/IMU) mounted on UAV and then the adjusted positions of the image trajectories are calculated by the software based on GCPs geo-tagging. After correcting IO and EO parameters following SfM initial estimates, the Multi-View Stereo (MVS) algorithm is applied to generate dense point clouds. Later, for photo-realistic representation, these point clouds should be arranged, interpolated, if necessary, densified, and textured. Then after, DSM is created depending on the threedimensional points. Ortho-rectification is used to generate the final mapping representation, which includes surface details that eliminated projective distortions from the original images. Output Coordinate System of image WGS 84 / UTM zone 38N. The orthophoto describes all features in a map-like projection. The accurate geometry provided by the orthogonal projection, combined with the representation of the scene in airborne photographs, helps even users with unskilled cartography to recognize, read and accurately calculate objects present in the area [23], see Figure 7. 


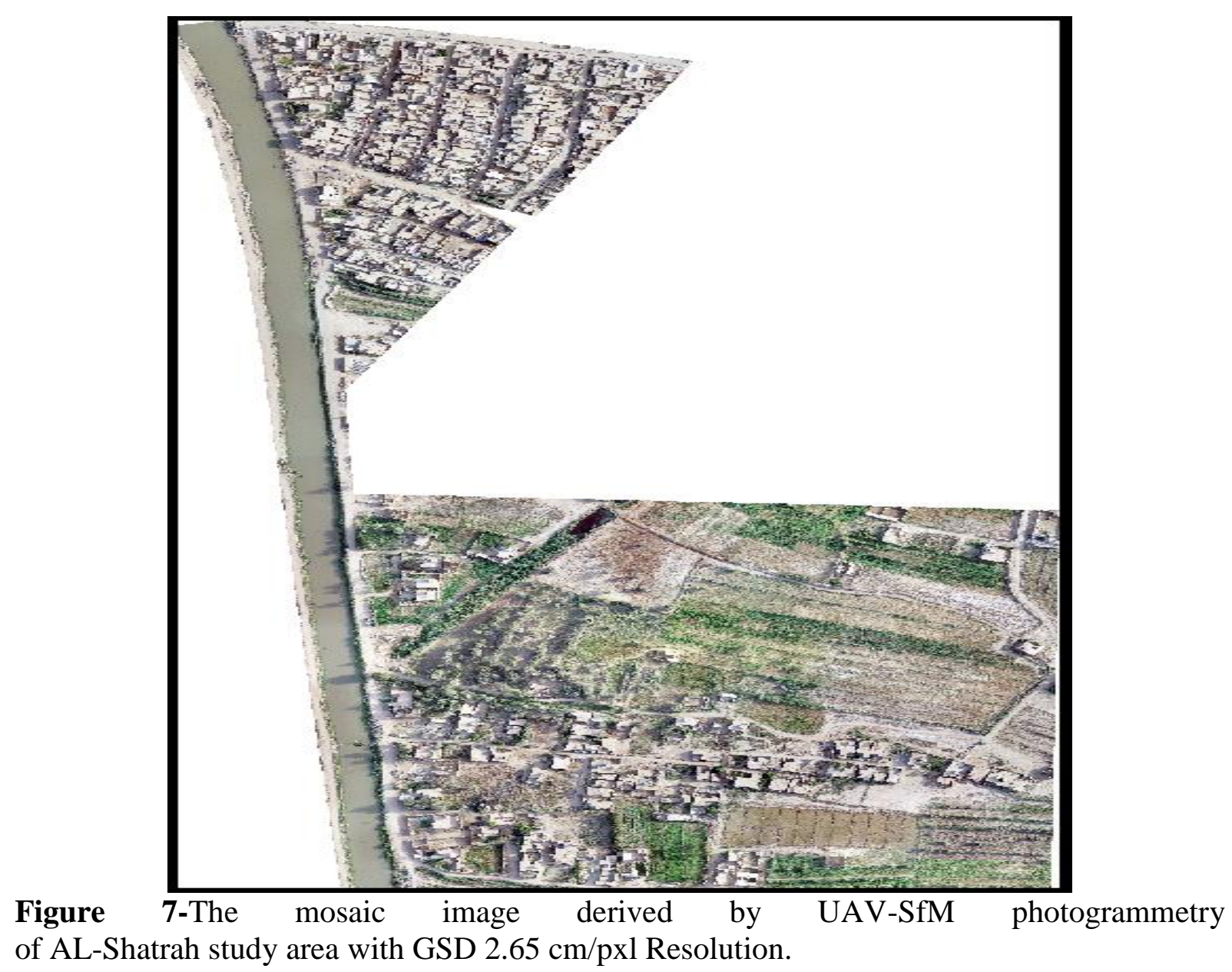

\section{Automatic Feature Extraction Approach}

The recent developments in Artificial Intelligence have greatly contributed to the automation of cadastral maps[24],[25]. Nowadays, automatic cadastral mapping based on UAV images have a very high resolution up to centimeters[1,11]. The automated or semi-automated feature extraction methods facilitates cadastral mapping production. Manual digitization is commonly seen as time intensive [26]. The automation starts from semi-automatic with human interaction to fully automatic. Because image interpretation is difficult, fully-automated extraction often display a certain error rate. Thus, human interaction cannot be fully exempt [27]. Nevertheless, in relation to cost and time, even a semi-automatic boundary extraction will dramatically change cadastral mapping projects positively. UAV images have the ability to automate object rebuilding and border extraction with high accuracy, low cost and less time [28]. The cadastral boundaries can represent naturally or human activities, such as roads, rivers, footpaths, hedges, fences, ditches, trees, water channels, walls of buildings, sidewalks, etc.[24]. This is mainly depends on remote sensing techniques based on its characteristics, including size, shape, area, ton color or texture and spectral value. [29]. These visible boundaries give the ability to be detected automatically from UAV data. In this research automatic feature extraction with some user interaction was applied following stages listed:

7.1 Segmentation: Obtaining a distinct segmentation is very important so that the segments match the number of buildings or parcels extracted as possible. The segmentation process was carried in this research following Multi-resolution Segmentation (MRS) algorithm in eCognition Developer software (www.trimble.com) version 9.5. MRS includes several parameters, which are scale parameter (SP), layers weight, shape and compactness [30]. In this paper, we had an RGB image with three layers. We gave them the same weights (layer 
weights determine the importance of each layer to the segmentation process). This helps to get objects more closely matched with the shapes based on the scale parameter, which is the main key control of segmentation by (MRS) method. The inappropriate scale value selection causes false merging results and thus remove some important boundaries and therefore the results (objects) are not visually homogeneous [15]. The homogeneity can be determined depending on the color and shape (smoothness + compactness) weights. The higher the shape or color value leads to a reduced role of the spectral information in extracting the boundaries, considering that color is the main component of image data. Always the compactness value is higher than the shape criterion: Color=1-shape; Shape=smoothness+compactness; Compactness $=(1-\beta$ compactness $) *$ shape and Compactness $=\beta$ compactness $*$ shape [31]. To avoid these errors, the area was subset into two parts, the upper part of the image (part 1) and the lower area (part 2). The purpose of this process was to fully control the segmentation process and obtaining more homogeneous areas, especially in areas with adjacent buildings, see Figure 8.

Part- 1 of the image contains a group of buildings and unequal streets, in addition to unpaved streets. This strong homogeneity between features creates a spectral and geometric complexity and causes confusion in the segmentation process. Thus, there were mixture between various features which makes it difficult to extract the boundaries in post-operations. As for part-2, it consists of wide green areas interspersed with paths way and some separate buildings, in addition to two water canals. The river is present along the study area.

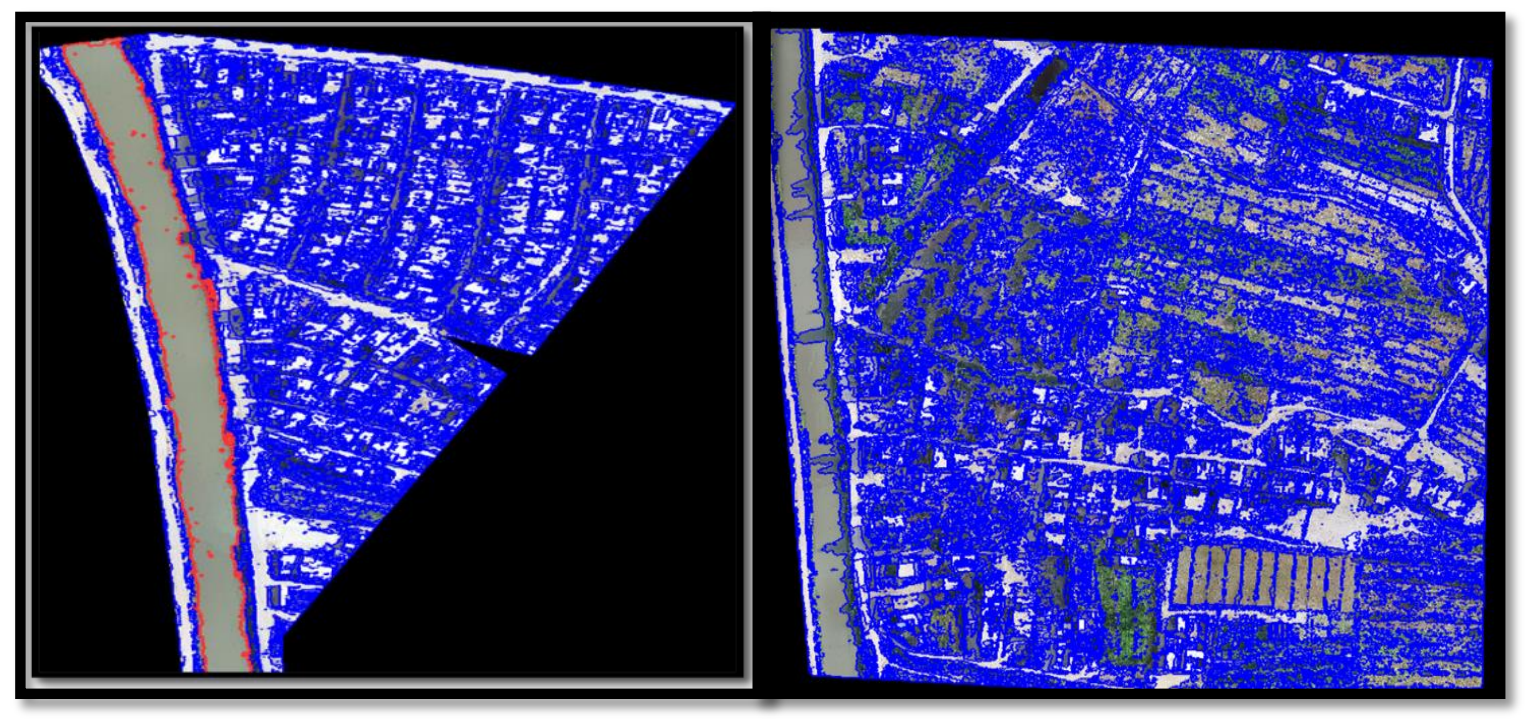

(a)

(b)

Figure 8-MRS segmentation of the mosaic image for: (a) part-1 by parameters ( $\mathrm{SP}=75$, Shape $=0.3, \mathrm{Comp}=0.8$ and Spectral Difference $=15)$, (b) part-2 by parameters $(\mathrm{SP}=75$, shape $=0.3$, Comp $=0.8$ and Spectral Difference $=20$ ).

7.2 Boundaries Extraction: Due to the complexity of the spectral area, we cannot use classification algorithms straight forward. At the same time, not all of the desired parcels could be obtained and whole right in one go, but they could be extracted in steps. choosing appropriate parameters for the first part may be contrary to the second part. The segmentation is performed more than once after each extraction of the features. The main dependence here was on the geometry information such as area, brightness or rectangular fit and Rel. border available in eCognition software to extract parcels. Below are details of the boundary's extraction process. 
- River: after the region was divided into two parts and we conducted the process of MRS segmentation, the formed objects at large and homogeneous areas that represent the shape of the river were presented in actuality form, see Figure 8. This was applied depending on the geometrical characteristics such as the area and merge all objects that have borders related to water at a ratio of $100 \%$. But not all parts of the river have been extracted. The river edges contain a lot of vegetation that must be identified and combined with the river class. We used the relation Borders feature (Rel. border to class) to identify these objects and combine them with the water class. Regarding the second part of the case study, we used the same approach applied in the first part to extract the boundary of the river. But because of the shade of the trees, limited homogeneous objects are obtained with an area covering the true shape of the river. We used brightness to the extracting the rest of the river boundaries, then we used the process of deleting and converting unclassified objects into the river class by means of the area features and common borders. As for the branch water channels, they are covered with dense plants, except for some small places. We performed a second segmentation process $(\mathrm{sp}=50)$ and then used the area feature to extract boundary and (Ratio vegetation) feature within a specified range, after applying a process to remove and transform the objects into the water class. This was located within the area to be classified and use crowing mode in pixelbased object resizing algorithm then re-classify and merge the delivered class. Pixel-based object resizing algorithm was utilized to smooth the boundary as shown in Figure 9.

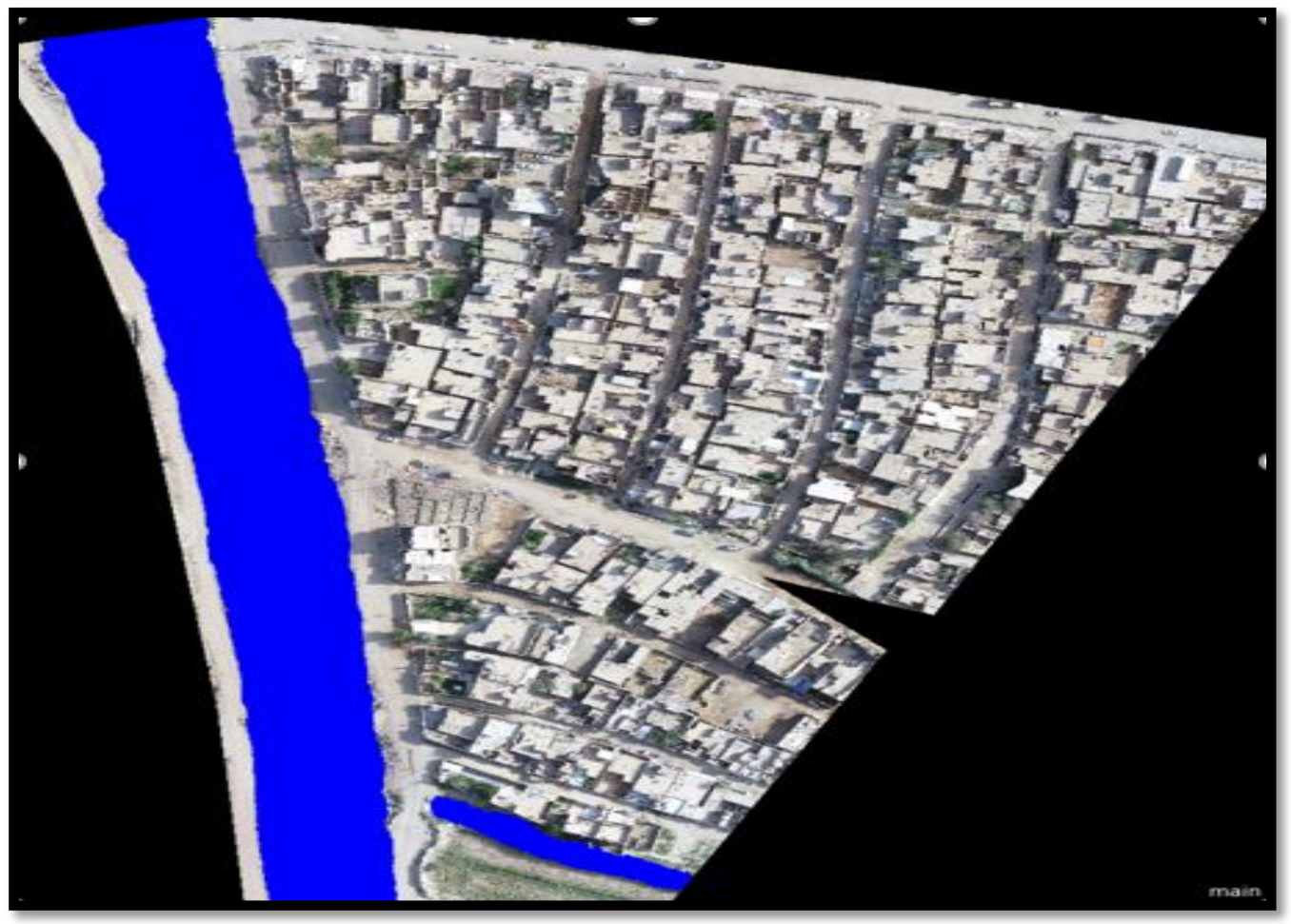

Figure 9-River automatic extraction of part-1of the study site.

- $\quad$ Roads: There are no paved roads designed in a geometric way in this study site. There is only one road upper the first part, but it is very discarded and covered with a dense layer of soils. As for the road along both sides of the river as shown in both parts, it was extracted by the expansion algorithm (pixel-based object resizing) in directions (x, y) applied until getting the road boundaries gradually, see Figure 10.

As for the remaining parts of the roads inside the neighborhood for part-1, firstly the MRS segmentation was applied with the parameters $(\mathrm{s} p=75$, shape $=0.3$, compactness $=0.8$ ). This carries out process after extracting the roads on both the river sides, then we used brightness 
and area feature to extract the roads. Further, using related borders (Rel. border to the road) helps objects to be transferred to road class. Then after, parcel boundary smoothing was applied to smoother appearance.

(a)

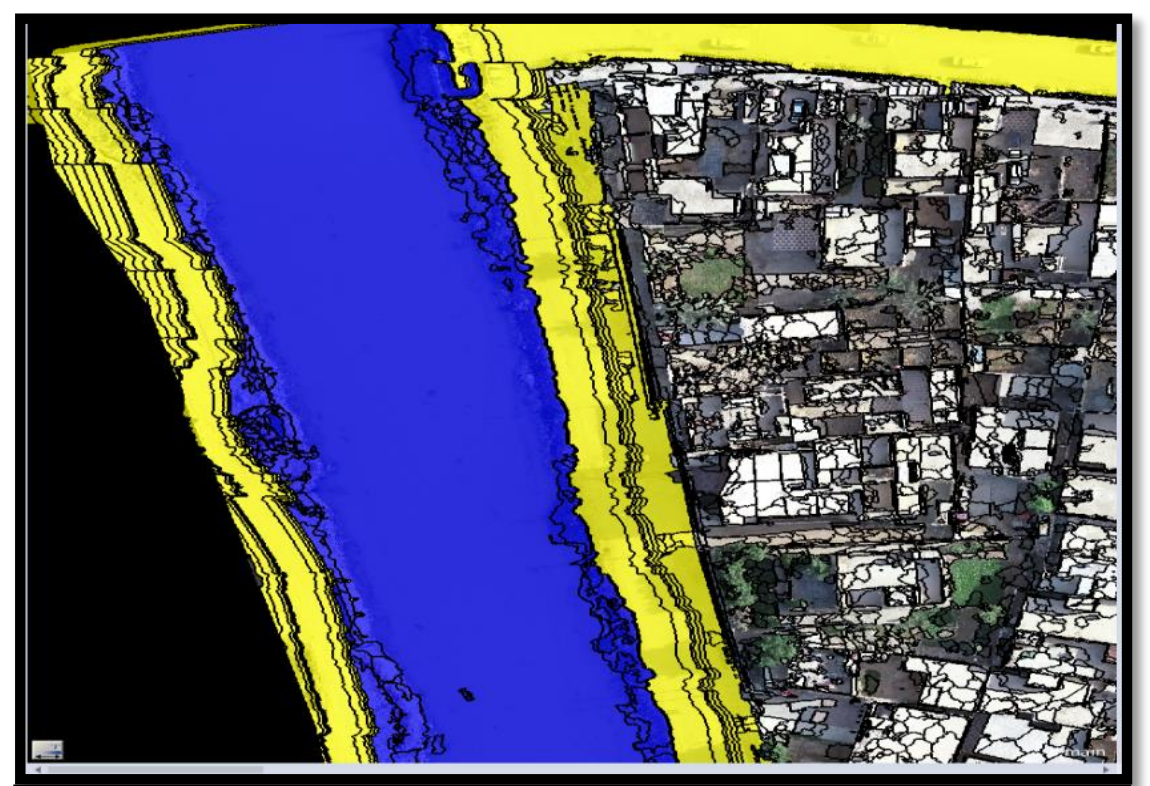

(b)

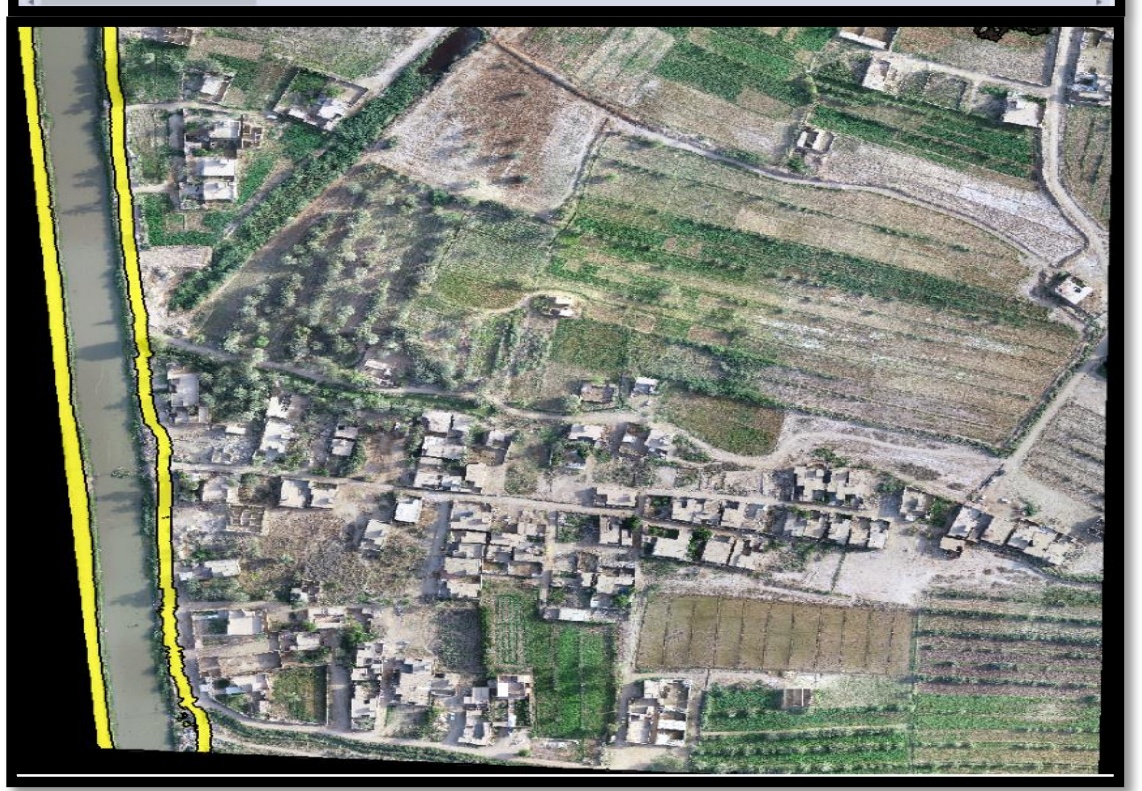

Figure 10-Illustrates automatic roads extraction (a) crowing mode by pixel-based object resizing algorithm to direction (x, y) for part-1. (b) Final extraction of Roads for part-2 of the study site.

- $\quad$ Streets: As for the streets those separate between the residential blocks, their shape tends to be regular approximately. We performed the segmentation process by (MRS) after the above boundaries extracted to obtain homogeneous objects that can be easily extracted due to the spectral similarity with the buildings. We used the area feature to determine the class of the streets and then the brightness feature, see Figure 11.

Here, objects are not explored by previous features and later created. They were converted by (Rel. border to the street) feature to individual street class. Later we performed a second segmentation $(\mathrm{sp}=30)$ to obtain smaller objects to avoid mixing with buildings and extract them by brightness. Then after, we used the algorithm (pixel-based object resizing) to smooth 
out the boundaries and remove excess and cracks. The borders also improved after the buildings were extracted and processed with the (QGIS) software, and returned with a new boundary. With streets, we used much more reclassifications steps than previous class, then smoothing the boundaries was also presence.

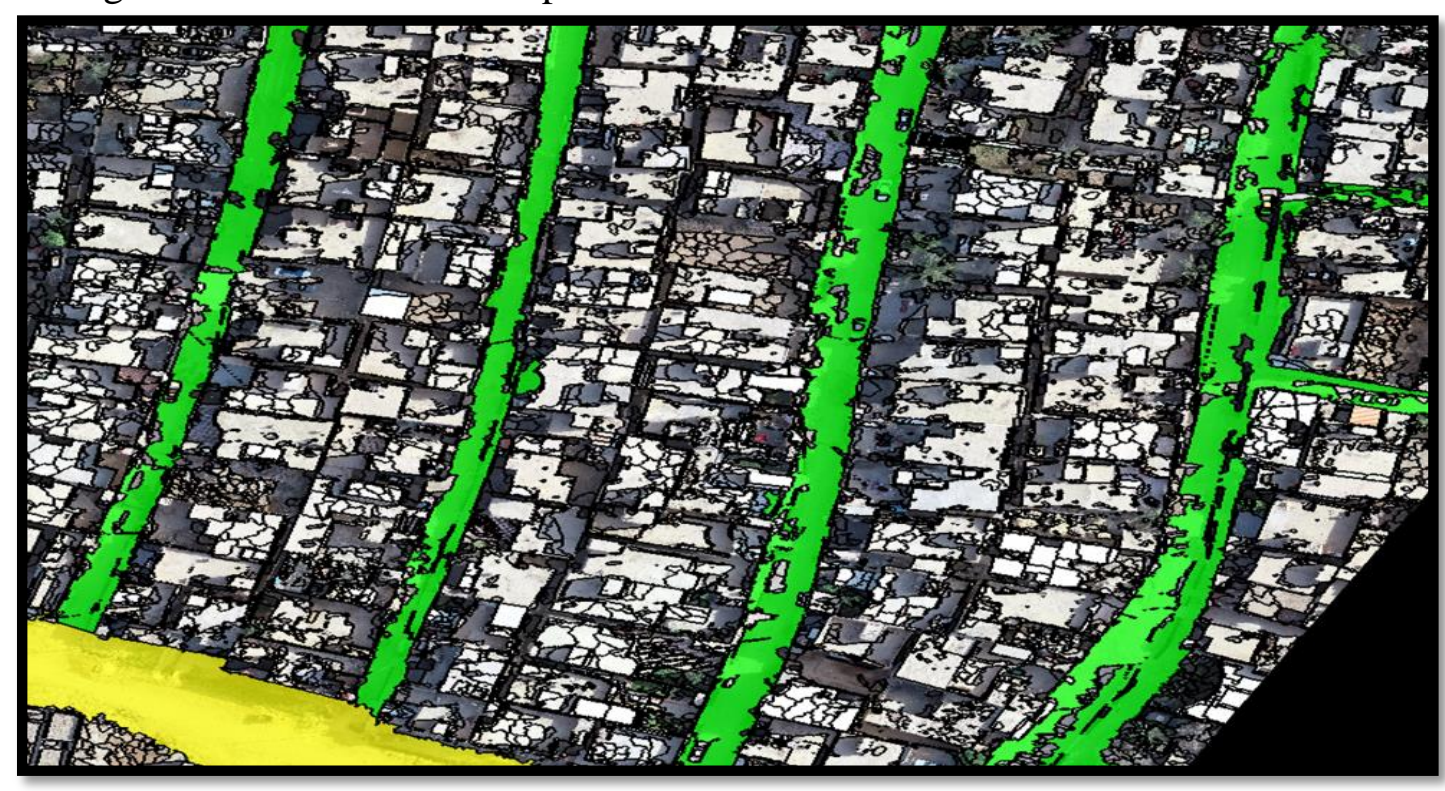

Figure 11-Street feature extraction using (Rel. border to) feature and remove objects to the street class.

- Unclassified Class: As a result of the non-engineering design of the neighborhood, we classified some irregular areas under the name (unclassified class) and extracted them by the algorithm (pixel-based object resizing) by (crowing mode) with some reclassification for the purpose of isolating the buildings from these other features.

- Buildings: The problem of the buildings is not in their extraction, but in how to separate them from each other, as the adjacent buildings are complex geometrically. After extracting the boundaries of the features, the buildings were determined automatically. It was polygons (block) representing a number of adjacent buildings (see Figure 12-a). In fact, most of the buildings are irregular in shape and area which complicates the process of separating them. We used the software (QGIS) to apply the mission and deliver more homogeneous class. It was divided based on the number of buildings. This division gives equal and regular area and shapes, this is contrary to reality as shown in Figure (12-b). So, we tried to match the real shape by editing the vertex that make up each polygon and then returning them to the eCognition software again. This step helped improving rest of the boundary adjacent to the buildings, especially the streets, see Figure (12-c). The last step was labor-intensive and timeconsuming despite the good result.

As for the buildings in the part-2, they were extracted using height data (NDSM) for the large number of independent buildings as shown in Figure (12-d). As for the adjacent buildings we used the same method in the first part, and then we performed deletions for the objects that were classified as buildings (trees). Then after, classification was re-applied to get rid of the objects that are not dependent to any class or those which may have a larger impact on the rest of the results. 


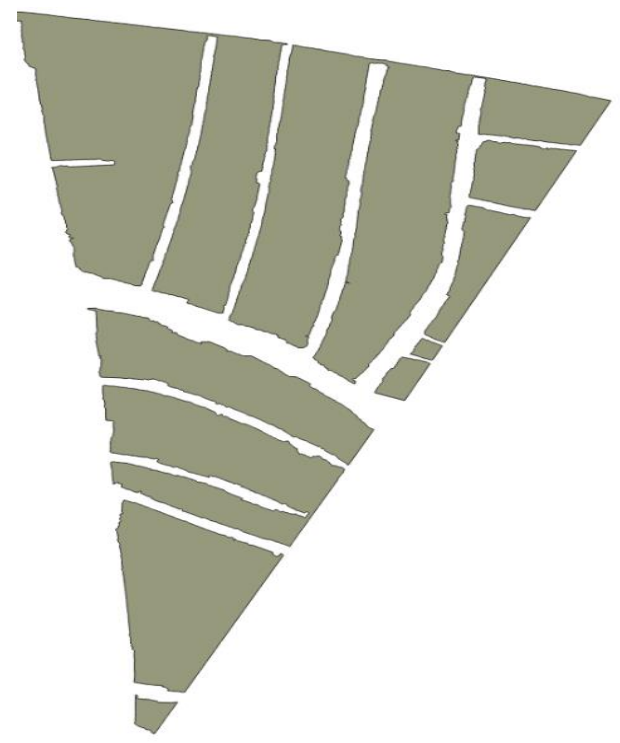

(a)

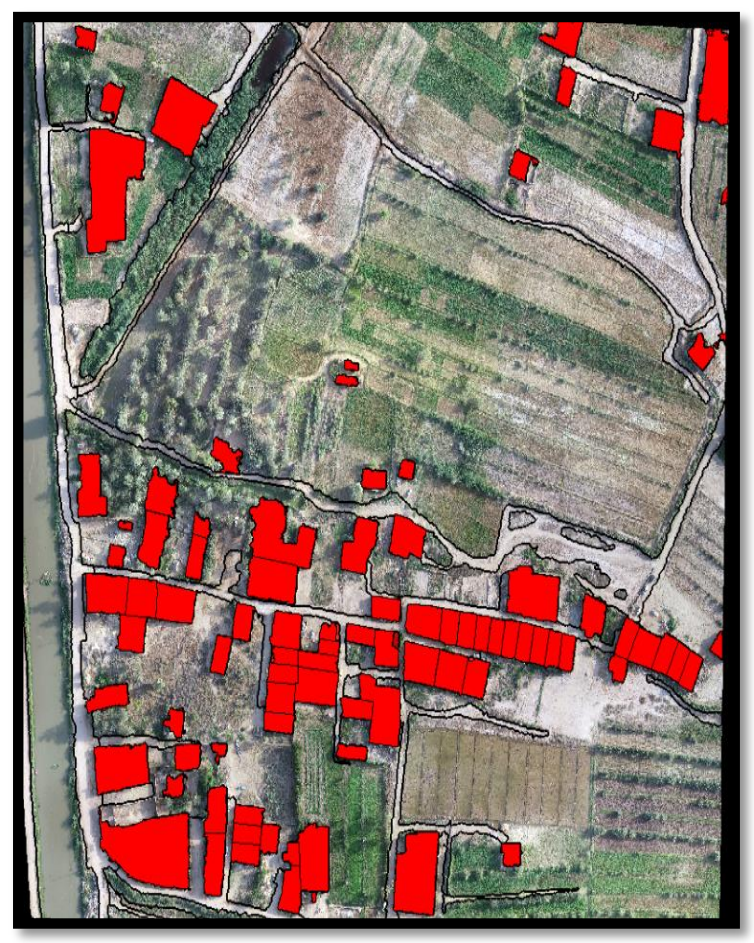

(d)

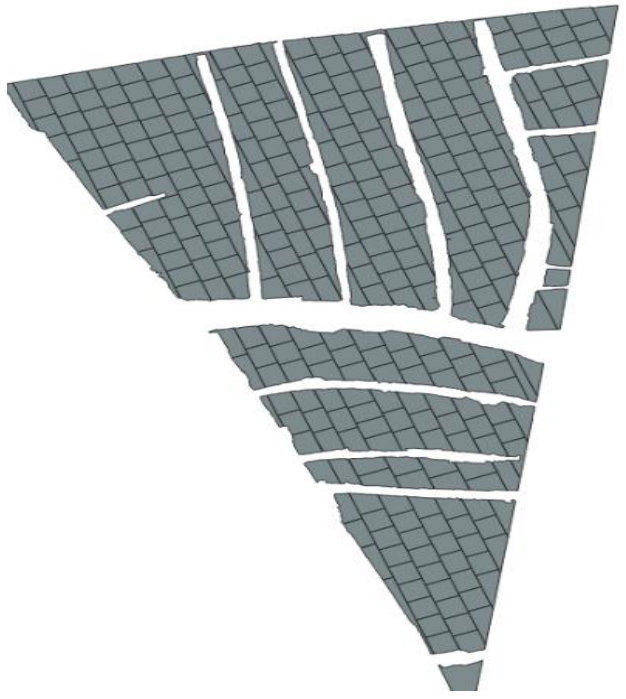

(b)

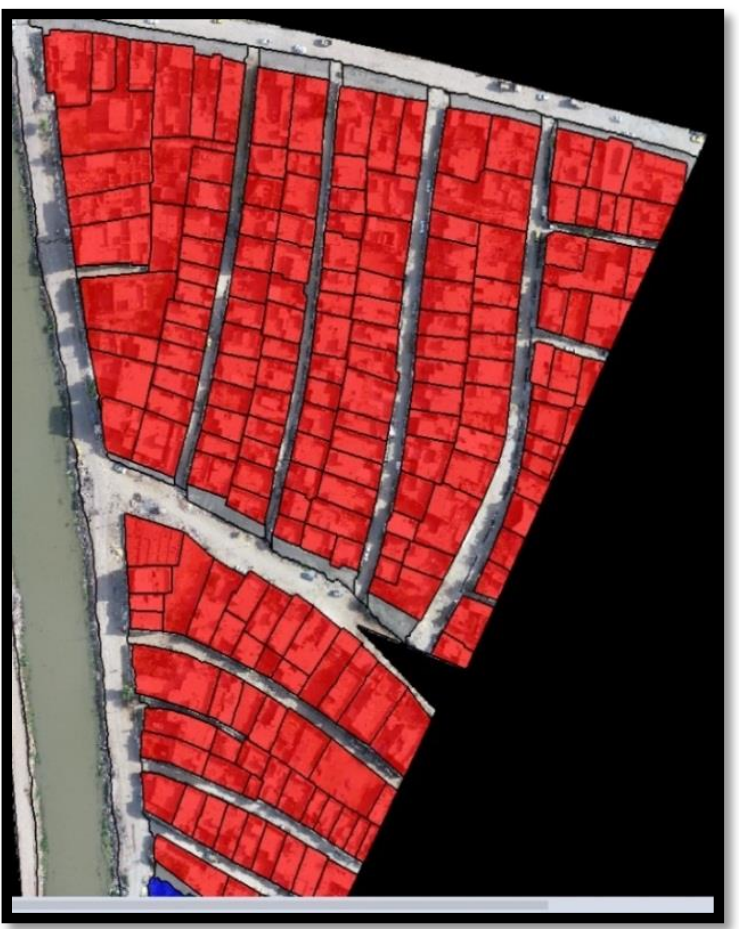

(c)

Figure 12- Illustrates automatic building extraction; (a) Polygons of the building before separate (b) Division of the polygons according to the number of buildings (c) Matching the shapes by editing the vertex (d) Extraction of buildings through (NDSM) for the part-2 of the region.

- $\quad$ Unpaved Roads: This class represents the dust roads (track) that were made according to the needs of each person (the owner of the land). Some of these roads are footpaths for people and paths for cars. In addition to the edge separating agricultural between lands (property). These tracks are soil purely and never paved before.

The method of extracting them was complicated due to mixing with uncultivated land that is spectrally similar to it. We relied on feature brightness in extracting these features (another 
characteristic can be used which is rectangular fit instead of brightness when applicable). We performed the segmentation (MRS) by size $(\mathrm{sp}=75)$ to obtain small objects (because the track was too narrow). Then we classified these tracks by using the brightness and area, then we removed all the unclassified objects and converted them to this class using the related borders and areas. Then we performed a second segmentation by size using smaller setting values than before $(\mathrm{s}=45)$ to improve the boundaries delivered from the above method by reclassifying objects that do not fit with the above method. Finally, we used the algorithm (pixel-based object resizing) to smooth the boundaries and as illustrates that in Figure 13.

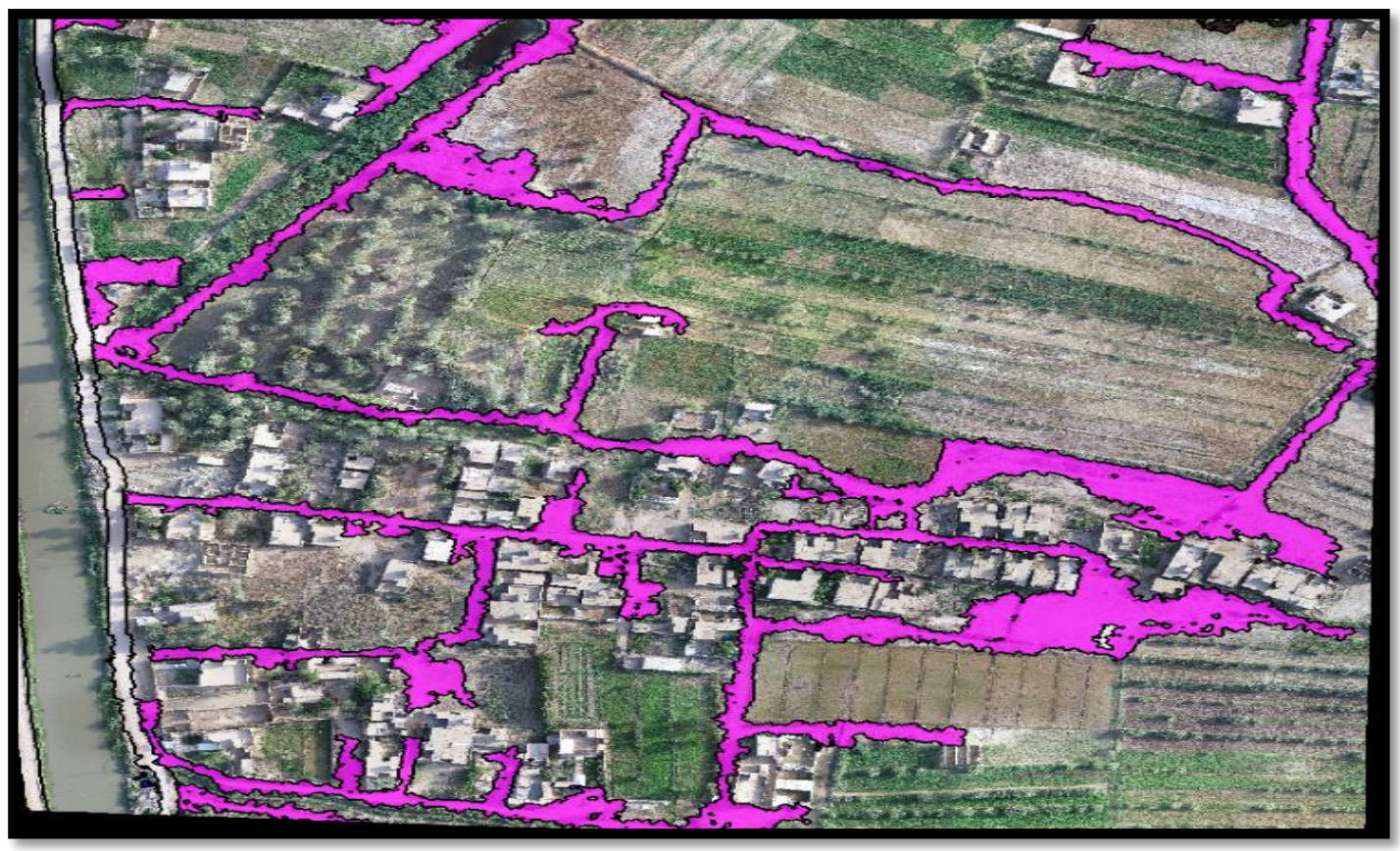

Figure 13-Extracting unpaved roads showing results before smoothing and remove ditches.

- Vegetation: This class was extracted automatically after extracting all the features by merging all unclassified objects under the name (vegetation) in part- 2 only. 
Figure 14 below shows the cadastral map of the case study after extracting all the boundaries.

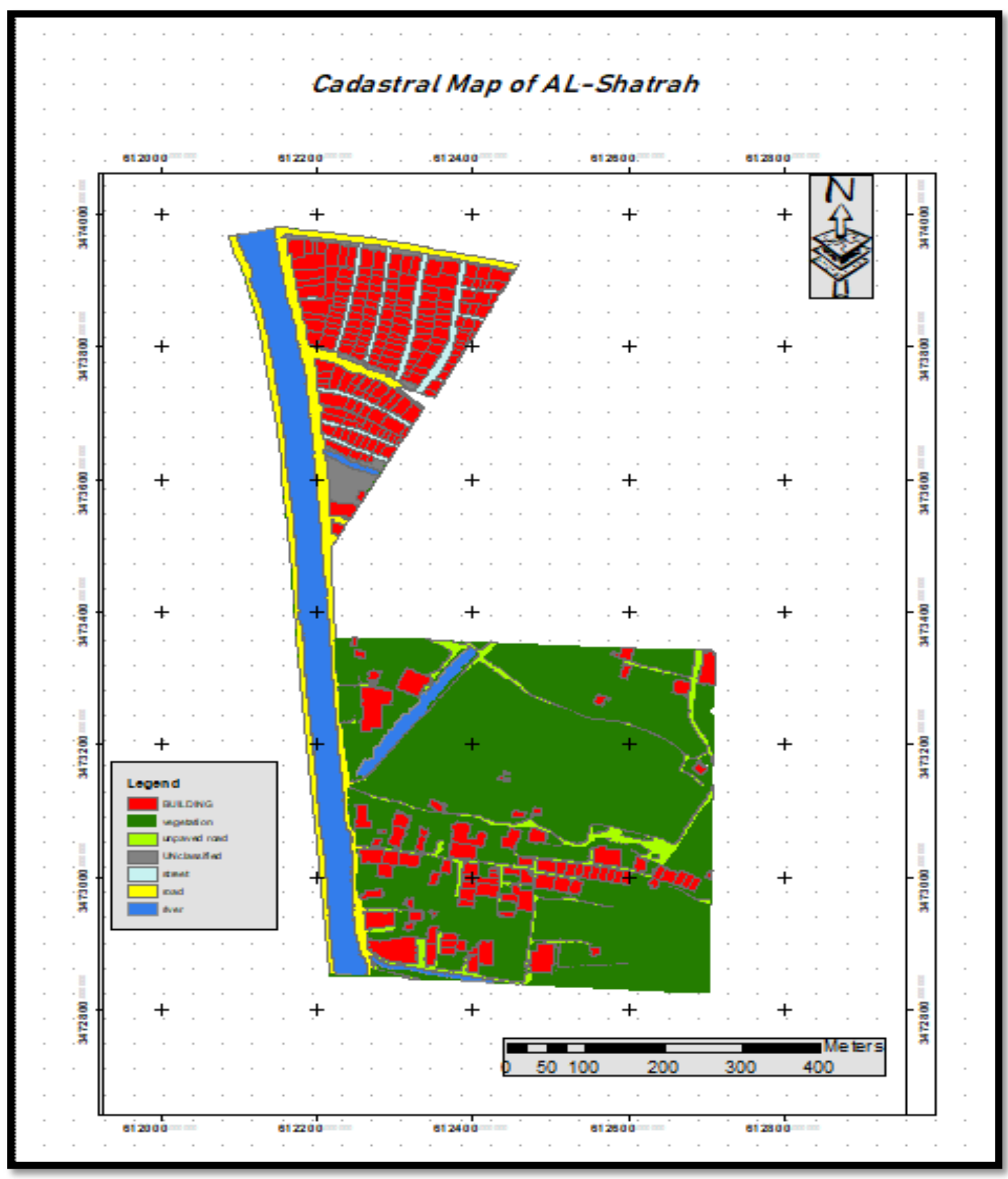

Figure 14-Illustrates the final digital cadastral map of part of the AL-Shatrah region in Iraq

\section{Evaluation of The Automatic Approach}

In order to evaluate the automatic feature extraction approach applied in this research, it is important to evaluate the automatic extraction boundary process with reference data set. This was applied by comparing automatic results with manual classification implementations, to compute the accuracy level of the automatic classification routine. Therefore, the interest region was classified manually into 7 classes based on the extracted mosaic image (the reference). These classes included (Building, Road, Street, Vegetation, River, unpaved roads, Unclassified class) using ARC MAP software and used the confusion matrix in the evaluation process, as illustrated in Table 1. 
Table 1-Confusion/Error matrix showing the accuracy of the automatic extraction routine

\begin{tabular}{|c|c|c|c|c|c|c|c|c|c|c|}
\hline & \multicolumn{9}{|c|}{ Manual extraction } \\
\hline & & $\begin{array}{l}\text { Buildin } \\
\mathrm{g}\end{array}$ & $\begin{array}{l}\text { Rive } \\
\text { r }\end{array}$ & $\begin{array}{c}\text { Roa } \\
\mathrm{d}\end{array}$ & Street & $\begin{array}{l}\text { Unpave } \\
\text { d Road }\end{array}$ & $\begin{array}{c}\text { Vegetatio } \\
\mathrm{n}\end{array}$ & $\begin{array}{c}\text { Unclassifie } \\
\text { d }\end{array}$ & $\begin{array}{c}\text { Tota } \\
1\end{array}$ & $\begin{array}{c}\text { User's } \\
\text { accuracy } \\
\%\end{array}$ \\
\hline \multirow{9}{*}{ 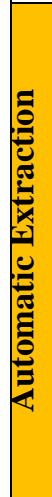 } & Building & 47 & 0 & 0 & 1 & 0 & 0 & 2 & 50 & 94 \\
\hline & River & 0 & 49 & 1 & 0 & 0 & 0 & 0 & 50 & 98 \\
\hline & Road & 1 & 1 & 44 & 0 & 0 & 1 & 3 & 50 & 88 \\
\hline & Street & 1 & 0 & 0 & 49 & 0 & 0 & 0 & 50 & 98 \\
\hline & $\begin{array}{c}\text { Unpaved } \\
\text { Road }\end{array}$ & 1 & 0 & 0 & 0 & 34 & 9 & 6 & 50 & 68 \\
\hline & Vegetation & 2 & 0 & 0 & 0 & 3 & 43 & 2 & 50 & 86 \\
\hline & $\begin{array}{c}\text { Unclassifie } \\
\text { d }\end{array}$ & 4 & 2 & 1 & 1 & 0 & 10 & 32 & 50 & 64 \\
\hline & Total & 56 & 52 & 46 & 51 & 37 & 63 & 45 & 350 & \\
\hline & $\begin{array}{l}\text { Producer's } \\
\text { accuracy \% }\end{array}$ & 84 & 94 & 96 & 96 & 92 & 68 & 71 & & 85 \\
\hline
\end{tabular}

The confusion matrix is used to evaluate the classification accuracy by the producer's accuracy and the user's accuracy. The User's accuracy describes the commission error or the accuracy represents the user point of view. Essentially, it shows how often the feature on the map represent and what it represents on the ground. This is referred to as reliability. User's Accuracy $=100 \%$-Commission Error. However, the producer's accuracy describes the omission error as a comparison of the reference dataset, where producer's Accuracy $=100 \%$ Omission Error. The yellow diagonal of the matrix refers to the true number of the feature sample, while the white elements of the matrix refer to the numbers of incorrectly classified features. The overall result of the automatic extraction is promising, as all classes were correctly delimited approximately, with the exception of the unpaved roads and unclassified classes.

The user's accuracy delivers very optimistic results over all classes. However, low accuracies of $64 \%$ and $68 \%$ of the unclassified and unpaved road classes was delivered respectively. This low accuracy level can be justified by the spectral similarity between these classes, which was difficult to identify features automatically. Further, it also due to the lack of the regular design of the locality, which made it difficult to determine the areas that are not classified within the specific parts. The producer's accuracy of the unclassified and vegetation classes was $71 \%$ and $68 \%$ respectively. However, this confirms the erroneous classification results for such areas. The overall accuracy was $88 \%$, which considered very promising.

\section{Conclusions}

This study motivation is absence of documented land rights or it is inaccurate that may lead to unstable properties security and life-threatening disputes a large people number without access to land management correctly after the analysis and investigation can as summarized below.

$>$ This research contributes to the development of a methodology for describing visible cadastral boundaries using UAVs imagery.

$>$ The proposed methodology is more automated because of the use of a rule set (deep learning) availability in eCognition software, and has proven to be less exhausting and time and more successful than demarcation by humans and with high accuracy and minimal human interventions (or nominal). The approach can work on different sensors data (aerial and satellite) of different resolutions.

$>$ eCognition Developer software has a great potential for analyzing images (automate, accelerate and enhance a variety of geospatial data interpretation). It includes a large number of segmentation and classification algorithms in addition to improving the boundaries, the 
OBIA rule-based expert systems contributed in an eCognition software to increase accuracy by automatically extracted boundaries (segmentation, several geometric features available and smoothness). but it lacks the final outputs of the maps.

MRS algorithm is suitable for obtaining homogeneous objects within the homogeneous feature, MRS results with optimized parameters such as scale and shape are used to extract boundaries without using classification algorithms, which indicates the strength of this algorithm. Parameters of MRS algorithm can be modified and applied according to the needed shape to be detected.

$>$ This research indicates, exploiting integration between spectral information alongside geometric information is a strong way to improve automatic object differentiation. It is critical for improving land-cover extraction performance.

$>$ Spectral uncertainty remains exists between classes of urban- LC and LU, such as bare soil and dry clay or building surfaces with roads, ultimately leading to errors in segmentation and classification.

$>\mathrm{n}$-DSM is effective in determining and extracting the height of urban features.

Method of dividing the buildings by QGIS software is successful, but time-consuming, and depends on final form resulting from extraction process.

$>$ However, the results have validated with reference manual results and proved the potential of the automatic extraction approach implemented for cadastral maps production and show distinctive improvements in the overall processing with semi-automatic approaches. This was highlighted through achieving an overall accuracy of $88 \%$. The workflow proposed can be used in growing countries to get more accurate results and up-to-date digital cadastral maps. Further, to accelerate production time frame it is important to formalize a tenure system for lands and assure availability of legal security for all properties.

$>$ Despite the accuracy of the extracted boundaries from UAV-based images, producing an accurate thematic map from images-based classifications above still a challenge, due to:(i) the urban landscape complexity; (ii) restrictions of chosen computer vision and techniques of image processing.

\section{References}

[1] X. Luo, R. M. Bennett, M. Koeva, and C. Lemmen, "Investigating semi-automated cadastral boundaries extraction from airborne laser scanned data," Land, vol. 6, no. 3, 2017, doi: 10.3390/land6030060.

[2] S. Crommelinck, R. Bennett, M. Gerke, F. Nex, M. Y. Yang, and G. Vosselman, "Review of automatic feature extraction from high-resolution optical sensor data for UAV-based cadastral mapping," Remote Sens., vol. 8, no. 8, 2016, doi: 10.3390/rs8080689.

[3] S. Crommelinck and M. Koeva, "Towards Cadastral Intelligence?," GIM Int., no. June, pp. 2729, 2019,

[4] P. F. Dale, "Cadastres and cadastral maps," Cartogr. J., vol. 14, no. 1, pp. 44-48, 1977, doi: 10.1179/caj.1977.14.1.44.

[5] M. Koirala, "Technology WJERT PROVIDED CADASTRAL SURVEY MAPS COMMENCING RISKS TO,” vol. 5, no. 2, pp. 263-273, 2019.

[6] P. Cichocinski, "Digital cadastral maps in land information systems," Lib. Q., vol. 9, no. 2, pp. 211-221, 1999, doi: 10.18352/lq.7535.

[7] Y. A. Wassie, "Toward Automatic Cadastral Boundary Mapping From Satellite Imagery Toward Automatic Cadastral Boundary Mapping From Satellite Imagery," 2016.

[8] R. Bennett, P. van Oosterom, C. Lemmen, and M. Koeva, "Remote Sensing for Land Administration," Remote Sens., vol. 12, no. 15, p. 2497, 2020, doi: 10.3390/rs12152497.

[9] R. Bennett, "Cadastral Intelligence, Mandated Mobs, and the Rise of the Cadastrobots. Presented at FIG Working Week 2016, May 2-5, 2016," no. May, 2016, [Online]. Available: https://www.fig.net/resources/proceedings/fig_proceedings/fig2016/papers/ts03a/TS03A_bennett _8335_abs.pdf. 
[10] S. C. Crommelinck, Automating image-based cadastral boundary mapping. 2019.

[11] M. Manyoky, P. Theiler, D. Steudler, and H. Eisenbeiss, "Unmanned Aerial Vehicle in Cadastral Applications," ISPRS - Int. Arch. Photogramm. Remote Sens. Spat. Inf. Sci., vol. XXXVIII-1/, no. September, pp. 57-62, 2012, doi: 10.5194/isprsarchives-xxxviii-1-c22-57-2011.

[12] B. Fetai, K. Oštir, M. K. Fras, and A. Lisec, "Extraction of visible boundaries for cadastral mapping based on UAV imagery," Remote Sens., vol. 11, no. 13, 2019, doi: 10.3390/rs11131510.

[13] S. Timilsina, S. K. Sharma, and J. Aryal, "Mapping Urban Trees Within Cadastral Parcels Using an Object-Based Convolutional Neural Network," ISPRS Ann. Photogramm. Remote Sens. Spat. Inf. Sci., vol. 4, no. 5/W2, pp. 111-117, 2019, doi: 10.5194/isprs-annals-IV-5-W2-111-2019.

[14] G. Khadanga, K. Jain, and S. Merugu, "Use of OBIA for extraction of cadastral parcels," 2016 Int. Conf. Adv. Comput. Commun. Informatics, ICACCI 2016, pp. 2226-2230, 2016, doi: 10.1109/ICACCI.2016.7732382.

[15] E. Nyandwi, M. Koeva, D. Kohli, and R. Bennett, "Comparing human versus machine-driven cadastral boundary feature extraction," Remote Sens., vol. 11, no. 14, pp. 1-23, 2019, doi: $10.3390 / \mathrm{rs} 11141662$.

[16] A. Z. Khalfa, I. A. K. Alwan, and N. H. Hamed, "Updating Urban Cadastral Map and Database Designing by GIS Using Aerial Photos," Eng. Technol. J., vol. 32, no. 8 Part (A) Engineering, pp. 2020-2029, 2014.

[17] O. Jasim, K. Hassoon, and M. Hussein, "Preparing a comprehensive geodatabase for Iraq geodetic networks systems," MATEC Web Conf., vol. 162, pp. 1-9, 2018, doi: 10.1051/matecconf/201816203030.

[18] I. Alwan, N. Hamed, and H. Husien, "Accuracy assessment of cadastral maps using high resolution aerial photos," MATEC Web Conf., vol. 162, no. January, 2018, doi: 10.1051/matecconf/201816203025.

[19] W. Y. Wan and I. P. Williamson, "A review of the digital cadastral databases in Australia \& New Zealand,” Aust. Surv., vol. 40, no. 1, pp. 41-52, 1995, doi: 10.1080/00050326.1995.10441663.

[20] A. A. Abdulhassan, A. A. Naji, and H. H. Abbood, "Vertical accuracy of digital elevation models based on differential global positioning system," Iraqi J. Sci., vol. 2021, pp. 91-99, 2021, doi: 10.24996/ijs.2021.SI.2.4.

[21] R. R. Muhammed and A. S. Mahdi, "Accurate Three Dimensional Coordinates Measurements Using Differential GPS Real Time Kinematic Mode," Iraqi J. Sci., vol. 59, no. 2C, pp. 11461151, 2018, doi: 10.24996/ijs.2018.59.2c.20.

[22] C. Xing, J. Wang, and Y. Xu, "Overlap analysis of the images from unmanned aerial vehicles," Proc. - Int. Conf. Electr. Control Eng. ICECE 2010, no. December, pp. 1459-1462, 2010, doi: 10.1109/iCECE.2010.360.

[23] A. Biasion, S. Dequal, A. Lingua, and T. Dipartimento, "A NEW PROCEDURE FOR THE AUTOMATIC PRODUCTION OF TRUE ORTHOPHOTOS Ort," Symp. A Q. J. Mod. Foreign Lit., no. August, 2004.

[24] Y. A. Wassie, M. N. Koeva, R. M. Bennett, and C. H. J. Lemmen, "A procedure for semiautomated cadastral boundary feature extraction from high-resolution satellite imagery," J. Spat. Sci., vol. 63, no. 1, pp. 75-92, 2018, doi: 10.1080/14498596.2017.1345667.

[25] M. Gao, X. Xu, Y. Klinger, J. Van Der Woerd, and P. Tapponnier, "High-resolution mapping based on an Unmanned Aerial Vehicle (UAV) to capture paleoseismic offsets along the AltynTagh fault, China," Sci. Rep., vol. 7, no. 1, pp. 1-11, 2017, doi: 10.1038/s41598-017-08119-2.

[26] F. Nex and F. Remondino, "UAV for 3D mapping applications: A review," Appl. Geomatics, vol. 6, no. 1, pp. 1-15, 2014, doi: 10.1007/s12518-013-0120-x.

[27] C. Heipke, P. A. Woodsford, and M. Gerke, "Updating geospatial databases from images," Adv. Photogramm. Remote Sens. Spat. Inf. Sci. 2008 ISPRS Congr. B., no. February 2014, pp. 335353, 2008, doi: 10.1201/9780203888445.ch26.

[28] I. Jazayeri, A. Rajabifard, and M. Kalantari, "A geometric and semantic evaluation of 3D data sourcing methods for land and property information," Land use policy, vol. 36, pp. 219-230, 2014, doi: 10.1016/j.landusepol.2013.08.004.

[29] Z. Ali, A. Tuladhar, and J. Zevenbergen, "Developing a framework for improving the quality of a deteriorated land administration system based on an exploratory case study in Pakistan," Nord. J. Surv. Real Estate Res., vol. 7, no. 1, pp. 30-57, 2010. 
[30] L. Drăguţ, O. Csillik, C. Eisank, and D. Tiede, "Automated parameterisation for multi-scale image segmentation on multiple layers," ISPRS J. Photogramm. Remote Sens., vol. 88, pp. 119127, 2014, doi: 10.1016/j.isprsjprs.2013.11.018.

[31] E. Nyandwi, "The battle of cadastral intelligence: Measuring the results of competition between people and machine in creation of cadastral boundaries," 2018.

[32] Trimble eCogntion software., 2019. eCognition Developer Rulesets, accessed May 3 2019, from http://www.ecognition.com 